\title{
Nem herói, nem vilão: elementos da prática médica na atenção básica em saúde
}

\author{
Neither a hero nor a villain: elements of medical practice \\ in primary care
}

Denizi de Oliveira Reis ${ }^{1}$

Luiz Carlos de Oliveira Cecílio ${ }^{1}$

Rosemarie Andreazza ${ }^{1}$

Eliane Cardoso Araújo ${ }^{1}$

Tiago Correia ${ }^{2}$

${ }^{1}$ Departamento de Medicina Preventiva, Universidade Federal de São Paulo. R. Borges Lagoa 1341, Vila Clementino. 04038 034 São Paulo SP Brasil. denizireis@gmail.com

${ }^{2}$ Instituto Universitário de Lisboa. Lisboa Portugal.

\begin{abstract}
This article describes the elements present in medical practice that contribute to understand its acknowledged low adhesion to the guidelines set forth by the Brazilian Primary Health Care (PHC) Policy. The empirical material produced by the two investigations of a qualitative nature led by the research team were put into use. In the first, in interviews involving managers and social control in cities the State of São Paulo, Brazil, physicians (acknowledged as central professionals for the construction of the Brazilian Unified Health System - SUS), are referred to as important assets to explain the difficulties to form a qualified primary health care service: the so-called "villain physicians." In the latter, ethnographic/cartographic research carried out in seven PHC Units in cities of São Paulo, with the use of scenes showing the doctors in action and/or thinking about their jobs, and the health team observing their work, more complex physicians emerge: fragile professionals with a reduced set of instruments to act before the "social factor" that invade their practices, threatened in their autonomy, finding it hard to engage in teamwork, dispossessed of their regulatory functions, and unaware of the space reserved for primary practices: decidedly human physicians - neither heroes nor villains.
\end{abstract}

Key words Medical practice, Primary health care, Quality Research
Resumo $O$ artigo sistematiza e discute elementos presentes na prática médica que contribuam para uma melhor compreensão da sua reconhecida baixa adesão às diretrizes da Politica Nacional de Atenção Básica (PNAB). Para tanto, fez uso de material empirico produzido em duas investigacões de caráter qualitativo conduzidas pelo mesmo grupo de pesquisa. Na primeira, entrevistas feitas com dirigentes gestores e controle social de dois municípios paulistas, os médicos são apontados como explicação importante para as dificuldades de se construir uma atenção básica qualificada e resolutiva: um "médico vilão". Na segunda, utilizou-se observação direta do cotidiano em sete unidades básicas de saúde em três municípios paulistas, com registros de cenas do médico em ação elou quando reflete sobre seu trabalho ou quando observado pela equipe. Emerge assim um médico mais complexo, fragilizado, com instrumental reduzido para atuar perante o "social" que invade seu consultório, ameaçado em sua autonomia profissional, com dificuldade de integrar-se ao trabalho em equipe, expropriado das funções regulatórias e nem sempre com clareza do lugar reservado para a clínica na atenção básica: um médico humano, demasiado humano, nem herói, nem vilão.

Palavras-chave Prática médica, Atenção primária em saúde, Pesquisa qualitativa 


\section{Introdução}

Na história da Saúde Coletiva brasileira encontra-se bem marcada a preocupação de superação da dicotomia entre assistência médica individual e saúde pública, para a qual o aporte das ciências sociais foi determinante ${ }^{1}$.

A reflexão acerca do trabalho médico e de suas práticas é um bom exemplo disso. Aspectos tratados em estudos já considerados clássicos na Saúde Coletiva, incluem questões da autonomia do trabalho médico ${ }^{2,3}$, da produção/reprodução de concepções formuladas pelos próprios médicos a respeito de seu trabalho ${ }^{4}$, assim como aspectos mais críticos ligados à mercantilização ${ }^{5,6}$, iatrogenização ${ }^{7}$ e aprisionamento do médico ao paradigma da biomedicina ${ }^{8}$. Talvez por conta de tais origens, o pensamento crítico, que foi marcante na fundação do campo, levou a que o médico ocupasse, quase sempre, o papel de "vilão". Sua baixa adesão ao projeto de viabilização de uma ampla rede de atenção básica, sua reconhecida preferência pelo hospital e consultório privado como settings ideais de prática, sua difícil adesão ao trabalho de equipe multiprofissional e uma prática centrada no cuidado individual, dita "curativista-medicamentalizante", que parece resistir sempre à atitude preventivista ${ }^{9}$, fazem com que os médicos, de modo bastante consensual, sejam apontados como uma das principais dificuldades para a viabilização do Sistema Único de Saúde (SUS).

Recentemente, a "questão médica" ganhou uma renovada visibilidade nacional, por conta do lançamento pelo governo federal do Programa Mais Médicos ${ }^{10}$. Desde as chamadas "jornadas de junho" de 2013, a dificuldade de acesso ao médico em várias regiões do país, incluindo a periferia das grandes cidades, que se agudizou, volta à cena o debate em torno da difícil fixação do médico na Atenção Básica em Saúde. Estas questões vêm sendo apontadas pela Organização Mundial de Saúde ${ }^{11}$ como um desafio comum a vários países, o que exige esforços concentrados e compartilhamento das práticas internacionais exitosas.

O presente artigo tem como objetivo aportar algumas indicações para melhor compreensão da prática médica nos serviços básicos de saúde, tentando identificar elementos que possibilitem o entendimento do médico que vá além da sua caracterização como "o" vilão da história. Por conseguinte, visa contribuir para a construção de novas relações analíticas entre os formuladores das políticas de saúde, os gestores e os médicos, quando se trata de pensar o papel da atenção básica.

\section{Metodologia}

O material empírico utilizado para a elaboração do artigo foi obtido em duas investigações diferentes $^{12,13}$. Ambas são de caráter qualitativo, conduzidas pelo mesmo grupo de pesquisa. Nelas, foi possível recolher material empírico consistente com o objetivo de reconhecer e problematizar elementos da prática médica que contribuam para uma melhor compreensão da baixa adesão dos médicos ao projeto de construção de uma atenção básica à saúde, tal qual definida na Política Nacional de Atenção Básica ${ }^{14}$.

Neste artigo, salienta-se um conjunto de aspectos que permitem caracterizar: 1) Pontos de vista contrastantes de atores do campo da saúde sobre os médicos; 2) o que pensa o médico sobre seu trabalho - o médico reflexivo; e 3) a relação dos médicos com os demais trabalhadores de saúde. Identificamos duas inovações analíticas no artigo. Uma, é a análise conjunta de discursos e de práticas na esteira da epistemologia interpretativa ${ }^{15}$. Outra, é a inclusão do "médico reflexivo" no contexto de debates, quer da socio$\operatorname{logia}{ }^{16}$, quer de áreas interdisciplinares como os estudos organizacionais ${ }^{17,18}$, que buscam interpretar o modo ativo como os profissionais produzem e refletem sobre suas práticas profissionais em contextos institucionais concretos.

Da primeira investigação, fazemos uso dos resultados encontrados em entrevistas em profundidade realizadas com dirigentes (prefeitos), gestores (secretários municipais) e participantes do controle social de dois municípios do ABC Paulista. Tendo como ponto de partida apenas a indagação como o senhor (a) avalia a saúde na sua cidade? E quais os principais problemas que chegam até o senhor (a)?, a "questão médica” emergiu de modo espontâneo e com muita força.

Da segunda investigação, fazemos uso da estratégia metodológica de observação direta do cotidiano das equipes de sete unidades básicas (UBS), localizadas em três municípios do estado de São Paulo. Duas delas localizadas no mesmo município do ABC paulista da primeira investigação, três na capital paulista, e duas em cidade do interior. Interessava-nos conhecer os processos ali desenvolvidos, entendidos aqui não como o conjunto de etapas definidas para a realização do trabalho em si (técnicas, tempos, protocolos, divisões, funções e estruturas), mas as experiências advindas das processualidades colocadas nas distintas práticas de cuidado e de gestão. Os pesquisadores de campo frequen- 
taram as unidades por períodos de oito a doze meses, no correr de 2014. Utilizamos os diários de campo produzidos nessas vivências para identificar o que havia de registro sobre o médico atuando (flagrantes da prática médica), os médicos falando espontaneamente sobre seu trabalho (o médico reflexivo) e a equipe falando sobre este profissional.

Ao mergulhar no material da segunda investigação, tivemos a certeza que fazia sentido ousar fazer a travessia entre as duas investigações. Quer dizer, a travessia de um plano mais externo à prática médica (gestores estratégicos falando sobre o médico), para um plano mais próximo a ela, propiciado pela segunda pesquisa.

\section{Resultados}

\section{A autonomia médica vista de fora}

Na primeira investigação, evidenciam-se vários pontos de convergência entre os discursos dos gestores com aqueles produzidos no campo da saúde coletiva. A dificuldade de fixação do médico é vista como um grande problema, uma ameaça ao projeto de construção de uma extensa rede de atenção básica que funcionaria como porta de entrada para o sistema público de saúde, como será possível observar nas falas abaixo relatadas.

Constroem-se hipóteses sobre tais dificuldades, como, por exemplo, a questão de "classe social" dos médicos, muito distante das classes populares, e a "corrida" desses profissionais por ganhos financeiros maiores em municípios vizinhos. Assim, os gestores não deixam de reconhecer a centralidade do trabalho médico nas unidades a partir de seus contatos com a população e, ainda, o quanto o modo como o médico realiza seu trabalho (algo que parece sempre escapar de seu controle) é fundamental para qualificar a atenção prestada.

Prefeito 2: [...] A gente tinha a UBS 2, ficou um período, mas aí veio o doutor A, que é um cara que fez história, tinha uma conceituação muito boa da Saúde da Família, ele deu uma levantada na UBS, ele vendeu o peixe lá. Então atenção básica ficou... Iluminou a unidade, ela passou a ser mais frequentada, o povo gostava $e$ tal, ficou uma referência.

Os entrevistados identificam diferenças entre os médicos, em particular as dificuldades de se encontrar "o bom médico", impacientam-se com a sua alta rotatividade, e depositam grande expectativa no bom trabalho deste profissional como algo capaz de solucionar boa parte dos problemas das altas demandas de atenção no sistema público, em particular na atenção básica.

Prefeito 2: Então, eu acho que é assim: a figura central [é] do médico... Eu não tenho um preconceito, mas eu acho que-é assim: eu tenho um degradé, desde o médico que eu acho que é um irresponsável, que é o que faz a disputa politica - porque é aquela coisa do cara atender o paciente e fazer campanha: "Ah, a Saúde tá uma merda". Até o outro lado, que é o doutor A, que é o cara meio "médico sem fronteira" [...] veste a camisa, que faz um puta trabalho, que a comunidade adora, onde você vai... É impressionante, isso dá um resultado! [...] se você tivesse todos os médicos do quadro ótimos, meus problemas estavam resolvidos [....]

Na Política Nacional de Atenção Básica, têmse construído diretrizes, orientações e normativas para a organização das unidades que privilegiem o cuidado para além da assistência médica. No entanto, os entrevistados manifestam frustração diante das tentativas de mudanças no modelo de atenção, em particular a força e a hegemonia do modelo biomédico no "imaginário" da população que valoriza as consultas médicas em detrimento de outras ofertas de cuidado, além de outros arranjos de cuidado propostos pela Secretaria Municipal de Saúde, como o acolhimento, por exemplo.

Secretária 2: [...] E uma coisa que eu fico impressionada é a capacidade de captura que tem esse modelo [da Medicina]. Você cria dispositivo, um mês depois capturou! Virou uma triagem pra consulta médica. Você cria outro, capturou. "Não, nós vamos fazer caminhada". "Tá, nós vamos fazer uma avaliação antes e depois": captura. O esforço brutal que você tem que fazer com os trabalhadores da saúde...

Pode-se dizer que os gestores atualizam a visão do médico como vilão, embora agora não mais pelas razões teórico-conceituais adotadas por certa matriz teórica do pensamento crítico fundante da Saúde Coletiva, mas por razões bem práticas, em particular que lhes parece ser a recusa do médico de ocupar o lugar central que lhe é reservado para a qualificação do cuidado. Os entrevistados reconhecem o (ainda) grande poder dos médicos, e o quanto estes (ainda) têm sabido resistir, em boa medida, a toda e qualquer estratégia de gestão do seu trabalho. Parecem dizer, em resumo e de modo simplificado, que ainda não existe o médico necessário para o projeto da atenção básica, indiretamente reforçando a imagem que está sendo usada do "médico-vilão". 
Veremos, a seguir, com dados da segunda investigação, e para além de qualquer julgamento moral do tipo "bom" ou "mau", como a prática de médicos, em contextos político-histórico-sociais concretos, assume nuances, modulações, limites, estranhamentos, "razões de ser", que escapam a qualquer tipo de julgamento generalizante. Essa é a travessia experimentada entre uma pesquisa e outra.

\section{O médico e sua prática na micropolítica da atenção básica}

$\mathrm{Na}$ segunda investigação, foi possível observar a prática médica na materialidade complexa e múltipla dos serviços, de algum modo premido entre as diretrizes das políticas de saúde, e as condições concretas de trabalho da equipe, longe do julgamento dos dirigentes e dos gestores. Como vimos antes, estabelecemos três ângulos de observação: o médico reflexivo; flagrantes da prática médica; a equipe observa a prática médica.

\section{O médico reflexivo}

Os registros captaram momentos nos quais os médicos fazem reflexões sobre sua prática, em particular como percebem ameaças à sua autonomia, como produzem sentidos para os "modelos assistenciais", nem sempre claros e nos quais devem atuar como ator central, e como se queixam ou criticam o modo como é feita a gestão, considerando-a ineficiente, burocratizada e muito "politizada". São várias as cenas em que eles fazem claras manifestações sobre ameaças ou perdas reais da sua autonomia no trabalho, em particular à gestão de sua agenda, como no registro abaixo:

[numa reunião de equipe] Quando [alguns profissionais] já estavam saindo [da reunião] entra a generalista $B[. .$.$] . Comenta sobre o caso da$ senhora que queria passar com ela pela manhã. Explica que não tem domínio sobre sua agenda, que está toda no sistema para agendamento na recepção, e que a muito custo conseguiu a $4^{\text {a }}$ feira pela manhã para gerenciar os casos que ela entende serem graves e que precisam de retorno rápido e para os casos trazidos pelas agentes na reunião de equipe. Como são casos mais complexos, exigem mais tempo de consulta e mais energia, por isso é um dia muito cansativo. Explica desta forma porque não deixa ter encaixe [neste dia]. UBS C

Percebe-se que a preservação de graus de autonomia representa um aspecto central para compreender a reflexividade dos médicos no
SUS hoje. Um registro de campo capta a discussão sobre trabalho em equipe, onde se pode perceber o desconforto e o desencontro dos médicos com os outros trabalhadores.

[numa reunião o ginecologista responde] Me considero um bom médico. Espero me aposentar logo. O negócio tá decadente. O nego abriu a carteirinha do pré-natal porque a paciente disse que estava grávida e foram pedindo exames. Ela tinha uma sindrome de ovário policístico e "Beta-HCG" negativo. Se ela sente dor e alguém abre: cadê o feto?! Se alguém pega essa carteirinha dá processo pra alguém aqui dentro. UBS D

A questão que esse material empírico salienta é a dependência crescente dos médicos em relação a outros profissionais para a condução de sua prática cotidiana. Como defende Schraiber ${ }^{18}$, isso não traduz necessariamente diminuição da autonomia técnica da medicina, mas a diminuição da sua autonomia organizacional, com o reforço da burocratização do cuidado e a crescente necessidade de negociação com outros profissionais, mesmo com aqueles que ocupam posições de dependência técnico-científica face ao médico.

A cena abaixo mostra uma profissional reconhecendo a dificuldade de "coordenar o cuidado a partir da Atenção Básica" como posto nos documentos oficiais ${ }^{14}$, em particular o desalento diante da falta de comunicação entre profissionais ou outros serviços envolvidos no atendimento do mesmo paciente. Entretanto, "sobraria" para os médicos as consequências dos atendimentos inadequado em outros níveis do sistema de saúde, incidindo diretamente na sua autonomia técnica.

[Na reunião da equipe] Ao ser apresentado um caso de insuficiência cardíaca, a médica reclama que não tem vontade de fazer mais nada sobre ele, pois já avaliou o caso, viu que precisava de internação e o caso foi devolvido pela UPA. O pastor então levou a mulher para o Hospital Especializado e ela ficou três dias internada. O enfermeiro se mostra preocupado, pois a paciente está com duas receitas, tomando medicação que não são compatíveis, uma da UPA e outra do hospital. A médica, apesar de desanimada, manda agendar a visita para rever e compatibilizar a medicação. UBS D

Cecílio et al. ${ }^{19}$ apontam que os médicos, sempre que podem, disputam a coordenação do cuidado de alguns pacientes e, em certas situações, com a regulação das instituições. Eles vão construindo "territórios profissionais" a partir de seu lugar de trabalho (consultório), utilizando redes de contatos informais, buscando indicar 'colegas' e serviços de sua confiança para produzir o cuidado que julgam necessário para seu pacien- 
te. Tal comunicação do médico com outros profissionais amplia as possibilidades dele realizar, em alguma medida, a coordenação do cuidado do seu paciente. O baixo grau de comunicação do médico que atua em unidades de saúde com outros pontos do sistema, parece ser uma das razões do estranhamento ${ }^{20}$ desse profissional com o seu trabalho.

Seria possível afirmar que as equipes, incluindo o médico, vivenciam um modelo de atenção, e seguindo as diretrizes oficiais da política de saúde, que é portadora de duas lógicas diferentes: uma que valoriza as ações de promoção, prevenção, de recorte mais programático, e outra, mais voltada para atividades clínicas, de consultação, de trabalho com o adoecimento fora da programação, traduzido muitas vezes como "demanda espontânea”. Enquanto formulação teórica tal modelo parece inatacável, mas de difícil operacionalização nas situações concretas, seja pelas carências materiais de toda ordem, seja pela pressão da demanda da população. É nesse território de tensões que se dá a prática do médico.

[Numa conversa com o médico] Perguntei por que era considerada uma vaga, se não levava 15 minutos o atendimento. O médico fica exaltado: "Por que eu não prestei concurso para trabalhar em Pronto Socorro! Se eu quisesse trabalhar em pronto socorro, eu prestaria concurso para lá. Eu trabalho em PS, e quanto estou lá eu atendo todo mundo, mas eu não quero trabalhar assim aqui! Se começar a atender todas as queixas que chegarem, isso aqui vira um PS!”. A opção de atender as queixas agudas que chegavam eram para ele um transtorno na qualidade do seu trabalho. $O$ excesso de demanda [...], caso ele atendesse às queixas agudas, claramente o incomodava. A visão de atenção básica para ele era uma atenção básica que conseguisse resolver os problemas do paciente, oferecendo um tempo e uma escuta adequada. Não oferecer isso, significaria uma sobrecarga de trabalho e má qualidade. "Esse não é o papel da Atenção Básica!” UBS B

\section{Flagrantes de prática}

Na segunda investigação vemos emergir um médico muitas vezes fragilizado, despreparado para enfrentar demandas, desafios, exigências que com certeza não fazem parte de sua preparação na escola médica e, de algum modo, não compõem o imaginário do que seja "ser médico”. Um personagem muitas vezes em dilema, com respostas empobrecidas, um médico que se vê incapaz de incorporar o "social" à sua prática ou ao seu agir operatório, impotente para dar respostas às demandas postas pelos usuários, movendo-se com desconforto por territórios de prática estranhas ao setting tradicional do consultório.

[numa visita domiciliar] A clínica $(G)$ ficou toda a consulta de costas para a Dona Maria, por que ela arrumou um lugar no muro para apoiar o prontuário e para escrever que era o único lugar com sombra. Ela ficou perto da dona Maria, mas ficou de costas. A enfermeira (S) começou a perguntar como ela estava, mediu sua pressão $e$ glicemia. Durante toda a visita a enfermeira (S) conversou e deu atenção a Dona Maria. A clínica $(G)$ fez apenas algumas perguntas para a filha da Dona Maria sobre os exames que tinha pedido da última vez. Senti o tempo todo que a Dra. Maria queria atenção da Dra. UBS A

No contraponto, há registros de bom vínculo do médico com o seu paciente - sua clientela. Aqui a responsabilização pela assistência à saúde continua a acontecer independentemente da norma do modelo de atenção, de atender apenas as famílias da área adscrita de uma equipe. O valor da autonomia médica se expressa ao vermos a ação de uma profissional que continua fazendo visita domiciliar a uma pessoa que não é mais da área de cobertura de sua equipe.

[...] a clínica (C) fala que a senhora (A) mudou de casa e consequentemente de área, na verdade nem faz mais parte da nossa cobertura, mas faz questão de continuar tratando da dona Ana. [...] A clínica conversa com a dona Ana, pergunta como ela tem passado, ela reclama que está inchando muito. A (C) recomenda ela usar meia de compreensão e beber bastante água. A doutora olha os exames, elogia a dona Ana e fala que vai diminuir os remédios. UBSA

O consultório do médico representa o setting de trabalho definidor da identidade da profissão, de muitas formas, o lugar do encontro privado entre o médico e o paciente/usuário. A relação médico-paciente tem sido objeto de muitos estu$\operatorname{dos}^{21,22}$ que abordam os objetivos e as dinâmicas relacionais presentes, bem como o papel de cada um dos sujeitos envolvidos, a potência gerada nestes encontros e o próprio valor terapêutico do médico. Já Michael Balint na Inglaterra na década de 1940 considerava que "o remédio mais usado em Medicina é o próprio médico o qual, como os demais medicamentos, precisa ser conhecido em sua posologia, efeitos colaterais e toxicidade" 23 . Nos registros de campo fica evidente a dificuldade do médico em lidar com situações da vida como a violência e a dor causada por ela, bem como outras situações clínicas 
que envolvam aspectos emocionais. A cena a seguir registra como o médico tem dificuldades de dar respostas mais adequadas a situações sociais, como após a ocorrência de uma chacina que teve alta repercussão na imprensa. Nesta e em outras situações, haveria a necessidade de uma proposta terapêutica multiprofissional com médico mais preparado para tanto.

Assim que a médica liberou uma paciente, eu e a enfermeira entramos na sala para discutir o caso com a médica. A enfermeira começa. A menina B é de uma das famílias que teve um jovem assassinado na última chacina. Quem está cuidando dela agora é a Fulana, lembra? (....) E ela tem vindo aqui quase diariamente com crises nervosas, depois que o irmão foi morto. A enfermeira explica um pouco mais do caso. A médica já lembra desanimada "o problema é que estamos sem ninguém da mental! e com certeza ela precisa de acompanhamento". "é que além disso ela está com algumas queixas clínicas, dor nas costas e uma otite que ainda não melhorou". (....) Chamamos a paciente que entrou com a sogra. Algumas coisas me chamaram a atenção no atendimento. A seriedade da médica pediatra criava um clima ainda mais tenso. Ela iniciou questionando sobre as queixas clínicas e definindo condutas para cada uma delas. A médica define a conduta clínica e pede alguns exames. Fico muito insatisfeito com a conduta dela. Pergunto se um retorno semanal com a enfermeira não seria possível nessas primeiras semanas, ao menos para conversar e ver como ela está se sentindo "eu acho que não, quando ela estiver com os exames eu vejo ela e se ela precisar ela pode voltar aqui" responde a médica. UBS B

A autoridade do médico consubstancia-se em um "saber fazer", instrumental, da ordem do prático, para além do saber científico que o embasa $^{24}$. Partindo dessa formulação da autora, poderíamos colocar em questão qual a autoridade médica é almejada no espaço de prática da atenção básica. As cenas a seguir mostram que alguns médicos sentem-se despreparados para atuar em certas situações de maior urgência, inclusive reconhecendo que sua escolha de trabalhar na Atenção Básica teria se pautado na suposição de que não haveria exigência de determinadas habilidades.

[A gerente da UBS] retomou [numa reunião] a questão da equipe que precisa ser montada para sábado - Atendimento Dengue [...] Ele já perguntou diretamente para a pediatra e representante do colegiado gestor da equipe azul se ela topava, e ela respondeu que por princípios não aceita. Ele perguntou para o clínico (L) e ele falou que não quer porque não gosta e faz muito tempo que não trabalha em pronto socorro. Eles começaram a insistir e ele falou que agora está muito nervoso porque tem uma senhora tomando soro lá em cima. Ela chegou à unidade com dengue e sua pressão estava 60 por 30 e que ele não aguenta essa pressão, por isso trabalha só nessa unidade. Fiquei comovida de ver um profissional falar abertamente de suas fragilidades ou dificuldades na frente de todos os colegas. UBS A

A seguir, uma cena na qual o médico é posto à prova, mostrando-se fragilizado a ponto de "abrir mão" de sua autoridade técnica.

[Num relato da auxiliar A] ligaram aqui falando que tinha uma viciada aqui na esquina dando a luz na calçada, a pediatra (B) da amarela foi lá e trouxe para dentro da unidade. Ela não poderia ter feito isso! Tinha que esperar o SAMU! Levaram a viciada que estava muito drogada para a sala da GO e a ginecologista $(\mathrm{N})$ não conseguiu ficar na sala e saiu, falou que não iria conseguir. Quem fez o parto foi a auxiliar (M) da [equipe] azul que trabalha em outro hospital especializado em mulheres, ela precisou ressuscitar a criança. UBS A

Os registros de cenas mostram a procura do médico por um "espaço" de cuidado - de trabalho - onde sua capacidade de resolver situações limites entre a vida e morte não fossem tão intensamente demandadas. A busca por um lugar de prática mais 'protegido' da dor e da complexidade da existência humana, onde pudesse atuar com ações mais controladas e programadas. De alguma forma o médico supõe que iria encontrar processos de adoecimento mais simples e supostamente menos complexos, como diabetes, hipertensão, puericultura e gestantes, com maior capacidade resolutiva. Porém, diferentemente do esperado se vê lançando a uma quantidade heterogênea de situações de vida, com muita vulnerabilidade social, violência e múltiplas carências. Um mundo "fora de ordem", que foge de qualquer plano prévio de atuação, pouco disciplinado ou controlado e de difícil resolução com as ferramentas operacionalizada pela medicina isoladamente.

\section{A equipe fala da prática médica}

A possibilidade real de o médico deixar a equipe a qualquer momento é um dos aspectos mais marcantes quando se analisam as cenas nas quais a equipe fala da prática médica. Para as equipes, parece que os médicos sempre que podem vão embora...

[Ela diz] Já a Equipe X é a "mais complicada”, "não pára médico". Pergunto se ela (arquivista) 
imagina o porquê, ela diz que é porque é uma área de favela e as pessoas são "muito agressivas e barraqueiras”. Me conta a curta trajetória de alguns médicos, e que na manhã de hoje a médica que chegou faz três meses foi embora porque não "tinha estrutura psicológica” para atender, pois foi "agredida verbalmente" por um paciente, mas ela não sabia ao certo o que tinha acontecido. UBS F

Os trabalhadores identificam grande autonomia dos médicos para o desenvolvimento de sua prática, seja na flexibilidade de que dispõem para gerir seu horário e sua agenda de trabalho, seja no comando técnico-científico que ainda mantém sobre o trabalho de toda a equipe.

No balcão da recepção um informe: "Não agendar consulta para o Dr. Valter as terças-feiras". Pergunto o motivo ao recepcionista e diz "ele é médico, eu que não posso escolher quando quero atender". Tento tirar algo mais, mas é improdutivo. Ele também informa que o Dr. Valter já atendeu hoje e não retorna (achei estranho, pois sua agenda é do dia todo). UBS G

Cenas registradas no acolhimento mostram como o atendimento de enfermagem parece não responder às expectativas dos usuários, que sempre pressionam por consultas médicas. Como principal dispositivo de abertura da unidade para a comunidade, o acolhimento é fonte de tensões e insatisfações, em especial porque carece de melhor articulação entre o trabalho do médico e o do enfermeiro para a prática mais compartilhada e solidária que faça frente à demanda por atendimento. Na cena a seguir, um enfermeiro fala claramente da difícil comunicação com os médicos para compartilhamento de decisões clínicas e de acesso a outros serviços, em especial o pronto socorro.

Ele [enfermeiro] se mostra irritado no momento. Fala que o "acolhimento" faz isso com ele. Ele se queixa que o acolhimento sobrecarrega o enfermeiro e mesmo assim não sente que seu trabalho ali é resolutivo. Tem que mandar as pessoas para o pronto socorro, mesmo as coisas mais simples, porque não tem vaga para o médico. No momento que converso com ele, entra na sala a enfermeira $C$ "se tivesse uma conversa mais aberta entre o enfermeiro e o médico"; "olha, é uma amigdalite"; "não custa ele falar - abre a boca!". Essa pressão pela vaga... O enfermeiro A fala que não mede esforços. Ele entra na sala e pede ao médico que resolva, mesmo sabendo que o médico poderá ir à direção reclamar que ele fez isso. UBS B

É interessante perceber como os trabalhadores têm clareza do caráter "de classe" presente nas dificuldades dos médicos em lidar com condições de trabalho na "periferia" (urbana, geográfica, mas principalmente "social").

[na sala de procedimentos] Logo no primeiro curativo, enquanto retirava as ataduras, [o auxiliar de enfermagem] revelou seu sonho de cursar medicina, mas nunca teve dinheiro suficiente para isso. Ele acredita que realmente faltam médicos no Brasil, e criticou as medidas tomadas pelo governo com o programa "Mais Médicos", pois acha que o governo deveria incentivar jovens da periferia a cursar a universidade de medicina ao invés de trazer médicos estrangeiros. UBS E

A partir de suas vivências, a equipe percebe os estranhamentos e as resistências do médico com alguns arranjos organizacionais como o acolhimento, em particular, por resultar em maior pressão por atendimento de demandas não programadas. Em última instância, falam das dificuldades no cotidiano de seus processos de trabalho advindas da centralidade que ainda goza o trabalho médico, uma vez que esta interfere e modula a produção da equipe e da unidade.

\section{Considerações finais}

Como se sabe, a política de saúde no Brasil, como em muitos outros países, tem insistido no reforço nos cuidados primários em saúde como o aspecto determinante na reforma e consolidação dos sistemas de saúde desde o último quartel do século $\mathrm{XX}^{25}$.

Percebe-se que o crescimento da Atenção Básica no nosso país desencadeou processos bastante complexos, com diferentes linhas de forças incidindo sobre o modo como o trabalho médico se dá neste lugar de prática. Há reconhecidos limites nas tentativas de mudanças no modelo de organização das unidades básica, em particular a superação da centralidade da consulta médica. As dificuldades para a necessária mudança de modelo de atenção são, em boa medida, explicada por resistências dos médicos que se sentem ameaçado em suas autonomias, bem como, por dificuldades da equipe de trabalhar com maior autonomia, mais “autorizada” para uma prática clínica mais resolutiva. Tudo isso reforçado pela difícil adesão, se não resistência, dos usuários aos arranjos organizacionais experimentados que, em tese, possibilitariam um modelo assistencial menos médico-centrado.

Contudo, vimos também como os gestores reconheceram a centralidade do trabalho do médico, sendo sua ausência entendida como um 
problema central para a população. Além disso, ficou ainda claro que os médicos podem abdicar de seu papel de autoridade técnica quando chamados a atender determinadas situações e/ou demandas dos usuários com doenças e sofrimentos de diferentes naturezas, incluindo os ditos problemas "sociais" que invadem o espaço da clínica.

Nessa medida, parece-nos ser possível afirmar que a reorganização da Atenção Básica, seguindo as diretrizes políticas da saúde, não deve passar necessariamente (ou exclusivamente) pelo reforço de mecanismos administrativos que buscam o maior controle da autonomia individual dos médicos, o que, aliás, tem sido descrito noutros estudos internacionais ${ }^{26}$. O incentivo para a responsabilização e o comprometimento dos médicos face à sua prática deve permitir ou incentivar o pleno uso de suas competências técnico-científicas em prol do doente.

Contudo, para isso acontecer, novas ações deverão acontecer no SUS. O material empírico demonstrou que os profissionais médicos nem sempre têm as competências necessárias para lidar com situações de alta vulnerabilidade vividas pelas pessoas. Encontramos o médico perdido perante situações complexas e desafiadoras. Longe de conseguir alcançar uma prática de "herói", ou seja, um profissional que interviria salvando vidas de modo dramático como no hospital ou em serviços de urgência/emergência, o trabalho na Atenção Básica coloca o médico frente a realidades e constrangimentos que escapam do seu controle, produzindo-lhe marcado sentimento de estranhamento, e muitas vezes de impotência. Por isso, menos que "vilão", e menos ainda herói, vimos um médico "humano, demasiado humano", submetido a condições nem sempre favoráveis à prestação do cuidado junto à comunidade.

A saída para os limites do médico em dar repostas adequadas para situações mais complexas que são atendidas diariamente na atenção básica, quer dizer, a necessidade de se produzir ofertas mais amplas e diversificadas do que consultas (e mais consultas) e procedimentos (e mais procedimentos) seria a formação de um trabalhador coletivo capaz de, ele sim, realizar uma clínica mais ampliada. A produção de tal trabalhador coletivo implica maior aproximação do médico com a equipe multiprofissional, o reconhecimento da equipe como aliada importante para uma prática mais resolutiva (e gratificante), coisa que o estudo mostra que não se realiza tão facilmente. É essa nova postura do médico que precisa ser desenvolvida na formação médica inicial. Impõe-se a necessidade de se repensar elementos centrais no ensino médico, em particular a realização do velho aforismo da medicina, que parece cada vez menos se realizar, de que é necessário cuidar do doente, e não da doença. É de se notar que visões mais tradicionais da autoridade médica percebidas pelos próprios médicos - sobretudo centradas na técnica e no hospital - têm reduzido de intensidade em outros países. A literatura vem descrevendo, com alguma precisão, o fato dos médicos não se oporem a novos modelos de cuidado centrados nas equipes e nos usuários e de serem submetidos à avaliação criteriosa, desde que sintam sua autonomia individual de decisão protegida e que os critérios de avaliação do desempenho sejam definidos de acordo com critérios médicos, e não a partir de visões altamente racionalizantes e padronizadas sobre o seu trabalho ${ }^{27-29}$.

O estudo empírico mostrou, ainda, um importante paradoxo entre o desenho da política e os seus resultados: a Política Nacional de Humanização fala do enriquecimento da prática médica, mas o que observamos no estudo foram médicos que se sentem com uma prática reduzida, afastados do que seria uma "clínica ampliada", submetidos a um espaço de atuação mais reduzido, com empobrecimento nas suas possibilidades de intervenção.

Como provocação, sugerimos o debate em torno da criação de estratégias de gestão "médicocentradas", que contribuíssem para uma reconstrução do sentido da autonomia médica. Claro que estamos falando à luz de uma nova cultura profissional tal como mencionamos anteriormente, que buscaria compatibilizar a autonomia médica com modelos de organização do trabalho mais solidários com os demais trabalhadores e com os usuários. Este tem sido um dos novos argumentos nos debates internacionais com alguma evidência empírica já comprovada ${ }^{30,31}$.

Sem desconsiderar as experiências com os dispositivos postos pela Política Nacional da Atenção Básica e de Humanização que trabalham nessa direção, o estudo aponta necessidade de "ajustes" de tais estratégias ou invenção de novos dispositivos para maior aproximação com os médicos. 


\section{Colaboradores}

DO Reis responsável pela concepção e desenho do artigo, análise dos dados, redação, revisão e aprovação da versão final. LCO Cecílio coordenador do grupo de pesquisa participou da concepção, desenho, redação, análise dos dados, revisão critica do conteúdo intelectual e aprovação da versão final. R Andreazza participou da análise e interpretação dos dados, redação, revisão crítica e aprovação da versão final. EC Araújo contribuiu na análise e interpretação dos dados, redação e aprovação da versão final. T Correia contribuiu no desenho do artigo, redação, revisão crítica do conteúdo intelectual e aprovação da versão final.

\section{Agradecimentos}

Aos pesquisadores do grupo de pesquisa Política, Planejamento e Gestão em Saúde do Departamento de Medicina Preventiva da Escola Paulista de Medicina da UNIFESP, e às equipes das UBS pela acolhida dos pesquisadores.

\section{Referências}

1. Nunes ED. A revista Ciência \& Saúde Coletiva e o processo de institucionalização de um campo de conhecimentos e práticas. Cien Saude Colet 2015; 20(7):19751982.

2. Donnangelo MCF. Medicina \& Sociedade. O médico e seu mercado de trabalho. 2a ed. São Paulo: Editora Hucitec; 2011.

3. Campos GWS. Os médicos e a política de saúde. São Paulo: Ed. Hucitec; 1988.

4. Schraiber LB. O médico e seu trabalho - limites da liberdade. São Paulo: Hucitec; 1993.

5. Mello CG. Saúde e Assistência Médica no Brasil. São Paulo: Hucitec; 1977.

6. Landmann J. A ética médica sem máscara. Rio de Janeiro: Guanabara; 1985.

7. Illich I. A expropriação da saúde. Nêmesis da Medicina. Rio de Janeiro: Nova Fronteira; 1975.

8. Clavreu J. A Ordem Médica. Poder e impotência do discurso médico. São Paulo: editora brasiliense; 1883.

9. Arouca S. O dilema preventivista: contribuição para a compreensão e crítica da medicina preventiva. São Paulo, Rio de Janeiro: Editora Unesp, Editora Fiocruz; 2003.

10. Brasil. Lei Federal no 12.871, de 22 de outubro de 2013. Institui o Programa Mais Médicos, altera as Leis $\mathrm{n}^{\circ}$ 8.745, de 9 de dezembro de 1993, e n ${ }^{\circ} 6.932$, de 7 de julho de 1981, e dá outras providências. Diário Oficial da União 2013; 23 out.

11. Organização Mundial de Saúde (OMS). The world health report 2008: primary care now more than ever. Genebra: OMS; 2008 .

12. Cecilio LCO. As múltiplas lógicas de construção de redes de cuidado no SUS: indo além da Regulação Governamental do acesso e utilização de serviços de saúde [relatório final]. São Paulo: Fapesp-PPSUS; 2012. [Processo Fapesp no. 2009/53098-2].

13. Cecilio LCO, Andreazza R. Atenção Primária à Saúde como estratégia para (re) configuração das Politicas Nacionais de Saúde: a perspectiva de seus profissionais e usuários [relatório final]. São Paulo: CNPq, Fapesp-PPSUS; 2015. [Processo CNPq no. 483460/2012-5; Processo Fapesp no. 2012/51258-5].Brasil. Ministério da Saúde (MS). Política Nacional de Atenção Básica. Série E. Legislação em Saúde. Brasília: MS; 2012.

14. Correia T. Interpretação e validação científica em pesquisa qualitativa. Interface (Botucatu) 2013; 17(45):263-274.

15. Correia T. Doctors' reflexivity in hospital organisations: The nexus between institutional and behavioural dynamics in the sociology of professions. Current Sociology 2017; 65(7):1050-1069.

16. Mutch A, Delbridge R, Ventresca M. Situating organizational action: The relational sociology of organizations. Organization 2006; 13(5):607-626.

17. Delbridge R, Edwards T. Inhabiting institutions: Critical realist refinements to understanding institutional complexity and change. Organization Studies 2013; 34(7):927-947.

18. Schraiber LB. O médico e seu trabalho - limites da liberdade. São Paulo: Hucitec; 1993.

19. Cecílio LCO, Aciole GG, Meneses CS, Iriart CB. A microrregulação praticada pelas operadoras investigadas. In: Brasil. Ministério da Saúde (MS). Agência Nacional de Saúde Complementar (ANS). Duas faces da mesma moeda. Rio de Janeiro: ANS; 2005. p. 75-140. 
20. Gomes RM. Trabalho médico e alienação: as transformações das práticas médicas e suas implicações para os processos de humanização/desumanização do trabalho em saúde. São Paulo [tese]. São Paulo: Universidade de São Paulo; 2010.

21. Capozzolo AA. No olho do furacão: trabalho médico e o Programa de Saúde da Família. Campinas [tese]. Campinas: Faculdade de Ciências Médicas de Campinas; 2003.

22. Caprara A, Rodrigues J. A relação assimétrica médicopaciente: repensando o vínculo terapêutico. Cien Saude Colet 2004; 9(1):139-146.

23. Balint M. O médico, o paciente e a doença. $2^{\text {a }}$ ed. Rio de Janeiro: Ateneu; 1975.

24. Schraiber LB. O Trabalho Médico: Questões Acerca da Autonomia Profissional. Cad Saude Publica 1995; 11(1):57-64.

25. Primary health care: report of the internacional Conference on Primary Health Care, Alma-Ata; USSR 6-12 September 1978. Nurs J India 1979; 70(11):285-295.

26. Lanier DC, Roland M, Burstin H, Knottnerus JA. Doctor performance and public accountability. Lancet 2003; 362(9393):1404-1408.

27. Grant S, Ring A, Gabbay M, Guthrie B, McLean G, Mair FS, Watt G, Heaney D, O’Donnell C. Soft governance, restratification and the 2004 general medical services contract: the case of UK primary care organisations and general practice teams. Sociol Health Illn 2015; 37(1):30-51.

28. Chen MS, Lee CB. Between professional dignity and economic interests-evidence based on a survey of Taiwan's primary care physicians. Int J Health Plann Manage 2013; 28(2):153-171.

29. Glen E, Randall A, Williams P. Health-care reform and the dimensions of professional autonomy. Canadian Public Administration 2009; 52(1):51-69.

30. Correia T, Denis JL. Hybrid management, organizational configuration, and medical professionalism: evidence from the establishment of a clinical directorate in Portugal. BMC Health Services Research 2016; 16(Supl. 2):161.

31. Plochg T, Klazinga NS, Starfield B. Transforming medical professionalism to fit changing health needs. $B M C$ Med 2009; 7:64.

Artigo apresentado em 14/03/2016

Aprovado em 23/08/2016

Versão final apresentada em 25/08/2016 